\title{
Hippocampal Brain-Derived Neurotrophic Factor Expression Following Treatment with Reboxetine, Citalopram, and Physical Exercise
}

\author{
Amelia A Russo-Neustadt*,', Hilda Alejandre', Celithelma Garcia', Autumn S Ivy' and Michael J Chen' \\ 'Department of Biological Sciences, California State University, Los Angeles, CA, USA
}

\begin{abstract}
The antidepressants, reboxetine and citalopram, were used in conjunction with voluntary physical exercise (wheel running) in order to assess the contribution of noradrenergic and serotonergic activation to enhancements in hippocampal brain-derived neurotrophic factor (BDNF) expression resulting from antidepressant treatment and exercise. Reboxetine (40 mg/kg/day), citalopram (I0 mg/kg/day), voluntary physical activity, and the combination of antidepressants with exercise were applied to rats for a range of treatment intervals (2 to 14 days). Hippocampal BDNF transcription levels (full-length BDNF, as well as exons I-IV) were then assessed via in situ hybridization. Reboxetine treatment led to a rapid (evident at 2 days) enhancement in BDNF transcription in several hippocampal regions. This increase was also observed when reboxetine treatment was combined with voluntary physical activity for 2 weeks. Treatment with citalopram led to an increase in BDNF mRNA in only one hippocampal region (CA2) after short-term (2 days) treatment, and when combined with exercise, increased BDNF mRNA in the CA4 and dentate gyrus after 2 weeks. As reported in previous studies, voluntary physical activity enhanced BDNF transcription in several hippocampal areas, both on its own and in combination with antidepressant treatments. Examination of the levels of individual BDNF transcript variants influenced by each of these antidepressants revealed distinct patterns of expression in response to the various treatments, and showed that exercise-plus-antidepressant produced significant changes where antidepressant alone failed. Overall, treatment with the norephinephrine-selective antidepressant, reboxetine, in combination with exercise, led to both rapid and sustained increases in hippocampal BDNF mRNA expression. The serotonergic agent, citalopram, appeared to require longer treatment intervals in order to influence BDNF expression positively.

Neuropsychopharmacology (2004) 29, 2189-2199, advance online publication, 16 June 2004; doi: I0.1038/sj.npp. 13005 I 4
\end{abstract}

Keywords: antidepressant; norephinephrine; serotonin; growth factor; physical activity; in situ hybridization

\section{INTRODUCTION}

Brain-derived neurotrophic factor (BDNF) is a molecule that influences not only neuronal survival, but also synaptic function and plasticity (Russo-Neustadt, 2003). Decreased BDNF expression is thought to play a role in the neurodegeneration and behavioral changes associated with chronic stress and depression, and restoring these levels may underlie the therapeutic responses to antidepressant medications (Duman et al, 1997). Much information has become available regarding the influence of physical exercise, antidepressant treatment, and other CNS-activating interventions on the expression of BDNF in the rat

*Correspondence: Dr AA Russo-Neustadt, Department of Biological Sciences, 515I State University Drive, Los Angeles, CA 90032, USA, Tel: + I 323343 2074, Fax: + I 3233436044 ,

E-mail: arusson@calstatela.edu.

Received 22 January 2004; revised 27 April 2004; accepted 18 May 2004

Online publication: 19 May 2004 at http://www.acnp.org/citations/ Npp05 190404028/default.pdf hippocampus. The combination of voluntary exercise and antidepressant treatment enhances the expression of hippocampal BDNF and that of its transcript variants in an additive manner (Russo-Neustadt et al, 1999), and evidence exists that monoaminergic activation is important for this effect (Garcia et al, 2003; Ivy et al, 2003). In the current study, we treated animals with the norepinephrine (NE)-selective antidepressant, reboxetine (Montgomery, 1999), and the highly serotonin (5-HT)specific antidepressant, citalopram (Sanchez and Hyttel, 1999), in order to assess the relative contributions of NE and 5-HT activation to antidepressant and antidepressant/exercise-associated increases in hippocampal BDNF expression.

Much evidence exists that exercise activates monoaminergic transmission in multiple brain areas (Dey et al, 1992; Dunn et al, 1996; Dishman et al, 2000; Molteni et al, 2002). Recent studies from our laboratory have demonstrated that both an NE-specific lesion and temporary blockade of $\beta$ adrenergic receptors remove the BDNF mRNA-enhancing effects of voluntary exercise (Garcia et al, 2003; Ivy et al, 
2003). In addition, both NE- and 5-HT-selective receptor antagonists such as propranolol, ketanserin, and WAY100635 reverse the BDNF-increasing effects of short-term treatment with the monoamine oxidase inhibitor, tranylcypromine (Ivy et al, 2003).

Acute forms of stress decrease the expression of hippocampal BDNF (Smith et al, 1995), and chronic, repeated stress leads to neurodegenerative changes and functional loss within the hippocampus (Kuroda and McEwen, 1998; Sapolsky, 2000). In one study from our laboratory, it was demonstrated that the combination of voluntary exercise with tranylcypromine treatment reversed the BDNF mRNA decline occurring with forced swimming, and also significantly increased total swimming time (Russo-Neustadt et al, 2001). In the Porsolt forced swim test, a variety of clinically efficacious antidepressants reverse the reduction in swimming time that occurs the day following the initial ( $15 \mathrm{~min}$ ) exposure to this inescapable stress (Cryan et al, 2002). Reboxetine has been shown to increase the most active behaviors observed during the forced swim test, such as climbing the walls of the cylinder (Page et al, 2003).

In the current study, the effects of exercise, antidepressant medications, and the combination of exercise/antidepressants on hippocampal BDNF mRNA levels were examined via in situ hybridization after a range of treatment intervals (2-14 days). As transcription of the BDNF gene is directed by several distinct promoters (Timmusk et al, 1993), individual variants of BDNF mRNA (containing exons I-IV) were examined for distinct regulation by antidepressants and exercise. Exercise has been shown to lead to rapid increases in exon II, and more sustained increases in exon I in several hippocampal regions. Synergy was evident for the expression of one of these variants (exon I) when chronic exercise and tranylcypromine treatment were combined (Russo-Neustadt et al, 2000). In the current study, we determined the transcript expression patterns of each type of antidepressant and their combination with exercise.

\section{MATERIALS AND METHODS}

\section{Subjects and Experimental Design}

All animal use procedures described below were conducted in strict accordance with the National Research Council's Guide for the Care and Use of Laboratory Animals (1996). All efforts were made to minimize the number of animals and any pain/distress they might incur. Male SpragueDawley rats $(n=115,350 \mathrm{~g}$; Charles River) were housed singly in polyethylene cages $\left(48 \times 27 \times 20 \mathrm{~cm}^{3}\right)$ with food and water ad libitum, and a $12: 12 \mathrm{~h}$ (06:00 to 18:00) light/ dark cycle.

Voluntary physical activity entailed free access to running wheels throughout the experiment. After a week of initial acclimation to the vivarium, rats were placed in polyethylene cages equipped with running wheels ( $34.5 \mathrm{~cm}$ diameter; Nalgene, Oregon). Distance traveled on the running wheel per 24-h period was recorded by computer using Ratrun software (C. Hage Associates, CA).

\section{Two-Day Study}

Animals received injections of reboxetine $(20 \mathrm{mg} / \mathrm{kg}$, i.p., b.i.d. at 09:00 and 17:00), citalopram via osmotic minipump (10 mg/kg/day, see below), or comparable volume of saline by pump or injection, respectively (controls). As 06:00 has previously been determined to be the time of peak diurnal baseline expression of BDNF (Berchtold et al, 1997), rats were killed at this time of day following their last treatment day. Animals were decapitated, the brains quickly removed and quick-frozen in an isopentane/dry ice bath, and stored at $-80^{\circ} \mathrm{C}$ until in situ hybridization experiments (see below). A total of six groups were used: saline, sedentary $(n=8)$; saline, physical activity $(n=9)$; reboxetine $(20 \mathrm{mg} /$ kg b.i.d., i.p.), sedentary $(n=5)$; reboxetine, physical activity $(n=5)$; citalopram (10 mg/kg/day, infusion), sedentary $(n=5)$; and citalopram, physical activity $(n=4)$.

\section{Seven-Day Study}

Conditions and parameters were identical to those in the 2day study, except that an experimental duration of 7 days, instead of 2 days, was employed. Again, a total of six groups were used: saline, sedentary $(n=9)$; saline, physical activity $(n=9)$; reboxetine, sedentary $(n=5)$; reboxetine, physical activity $(n=5)$; citalopram, sedentary $(n=6)$; and citalopram, physical activity $(n=7)$.

\section{Fourteen-Day Study}

Adult male Sprague-Dawley rats were housed singly in cages as in the previous experiments, above. After 1 week of initial acclimation to the vivarium, rats were surgically implanted (09:00) in the mid-scapular region with osmotic minipumps (Alza, Palo Alto, CA), which continuously infused drug (saline, reboxetine, or citalopram) subcutaneously; citalopram $(10 \mathrm{mg} / \mathrm{kg} /$ day $)$ or reboxetine $(40 \mathrm{mg} /$ $\mathrm{kg}$ /day) was administered over 14 days. These rats were allowed free access to their running wheels for the duration of the experiment (14 days). A total of six groups were used: saline, sedentary $(n=5)$; saline, physical activity $(n=7)$; citalopram, sedentary $(n=6)$; citalopram, physical activity $(n=7)$; reboxetine, sedentary $(n=6)$; and reboxetine, physical activity $(n=7)$. Reboxetine was infused via osmotic minipump in this experiment because sores developed on injection sites when reboxetine was administered i.p. for more than 7 consecutive days (Pharmacia, personal communication).

cRNA probes, in situ hybridization, and data analyses. Construction of cRNA probes, in situ hybridization, and data analyses were performed as previously described (Russo-Neustadt et al, 2000). Statistical significance of results were determined using one-way ANOVA and subsequent Fisher's PLSD for multiple comparisons.

\section{RESULTS}

\section{Two-Day Study}

Within 2 days, reboxetine treatment led to a significant increase in total BDNF mRNA in all hippocampal regions 
examined (Figure 1a): CA1 (125\% of control, $\mathrm{F}_{(3,24)}=2.70$, $p=0.04)$; CA2 $\left(165 \%, \mathrm{~F}_{(3,24)}=5.21, p=0.003\right)$; CA3 $(156 \%$, $\left.\mathrm{F}_{(3,24)}=4.96, \quad p=0.007\right) ; \quad$ CA4 $\quad\left(168 \%, \quad \mathrm{~F}_{(3,24)}=7.07\right.$, $p=0.004)$; and dentate gyrus (DG) $\left(156 \%, \mathrm{~F}_{(3,24)}=4.58\right.$, $p=0.003)$. Reboxetine treatment also elevated exon II mRNA levels in the CA2 (Figure 1c: $300 \%$ of control, $\left.\mathrm{F}_{(3,18)}=6.617, p<0.001\right)$.

Voluntary exercise for 2 days significantly increased fulllength $\mathrm{BDNF}$ in the CA4 $\left(139 \%\right.$ of control, $\mathrm{F}_{(3,24)}=7.07$, $p=0.041)$ and DG $\left(133 \%, \mathrm{~F}_{(3,24)}=4.58, p=0.032\right.$; Figure $\left.1 \mathrm{a}\right)$. In all, 2 days of activity also elevated exon II levels in the CA4 $\left(193 \%, F_{(3,21)}=3.09, p=0.028\right)$ and DG $(165 \%$, $\mathrm{F}_{(3,21)}=3.88, p=0.026$; Figure $\left.1 \mathrm{c}\right)$.

The combination of reboxetine and exercise increased total BDNF levels to a degree comparable to reboxetine alone in all hippocampal subregions examined after 2 days of treatment (Figure 1a). Exon I was elevated in the CA4 region with the combination of reboxetine and exercise, to a degree greater than either treatment alone (Figure 1b: $205 \%$ of control, $\left.\mathrm{F}_{(3,23)}=6.517, p<0.001\right)$. Exon II showed significant increases in the CA1, CA2, CA4, and DG with reboxetine-plus-exercise: CA1 $\left(265 \%, \quad \mathrm{~F}_{(3,18)}=2.964\right.$, $p=0.017) ; \quad$ CA2 $\left(261 \%, \mathrm{~F}_{(3,18)}=6.617, p=0.006\right) ; \quad$ CA4 $\left(226 \%, \quad F_{(3,21)}=3.088, \quad p=0.016\right) ; \quad$ and $D G \quad(207 \%$, $\mathrm{F}_{(3,21)}=3.88, p=0.004$ (Figure 1c)). Exon III was increased in all hippocampal regions examined following 2 days of reboxetine-plus-exercise: CA1 $\left(190 \%, \quad \mathrm{~F}_{(3,21)}=2.728\right.$, $p=0.014) ; \quad$ CA2 $\quad\left(192 \%, \mathrm{~F}_{(3,21)}=2.738, \quad p=0.024\right) ; \quad$ CA3 (185\%, $\left.\quad \mathrm{F}_{(3,22)}=6.471, \quad p=0.001\right) ; \quad \mathrm{CA} 4 \quad(169 \%$, $\left.\mathrm{F}_{(3,21)}=1.957, p=0.041\right)$; and $\mathrm{DG}\left(204 \%, \mathrm{~F}_{(3,22)}=3.256\right.$, $p=0.006$ (Figure 1d)). The combination of reboxetine with exercise clearly led to a greater influence on the expression of BDNF transcript variants I-III than reboxetine alone at this time interval. On the other hand, the 2-day reboxetine treatments led to no significant changes in exon IV, with or without exercise (Figure 1e).

After 2 days of treatment, citalopram increased full-length BDNF mRNA levels only in the CA2 (208\% of control, $\mathrm{F}_{(3,19)}=1.88, p=0.037$; Figure 2a). Short-term citalopram treatment had a significant influence on the expression of the transcript variants, exons II and IV. Citalopram significantly decreased exon II levels in the CA1 $(56 \%$ of control, $\left.\mathrm{F}_{(3,19)}=9.40, \quad p=0.016\right)$ and $\mathrm{CA} 3 \quad(62 \%$, $\mathrm{F}_{(3,19)}=23.53, \quad p=0.007$; Figure 2c), and significantly elevated exon IV levels in the CA4 region (137\%, $\mathrm{F}_{(3,19)}=5.71, p=0.025$; Figure 2e).

In this group of animals, short-term exercise significantly elevated full-length BDNF levels in all hippocampal areas except the CA2 (Figure 2a): CA1 (252\% of control, $\left.\mathrm{F}_{(3,19)}=2.30, \quad p=0.019\right) ; \quad \mathrm{CA} 3 \quad\left(178 \%, \quad \mathrm{~F}_{(3,19)}=2.99\right.$, $p=0.022)$; CA4 $\left(246 \%, \mathrm{~F}_{(3,19)}=2.70, p=0.014\right)$; and $\mathrm{DG}$ $\left(232 \%, \mathrm{~F}_{(3,19)}=3.09, p=0.011\right)$. There was also a striking elevation of exon I mRNA in the CA1 $\left(456 \%, \mathrm{~F}_{(3,19)}=3.12\right.$, $p=0.027)$, and significant increases in exon I in the CA4 $\left(187 \%, \quad \mathrm{~F}_{(3,19)}=4.54, \quad p=0.009\right) \quad$ and $\mathrm{DG} \quad(288 \%$, $\mathrm{F}_{(3,19)}=9.40, p<0.001$; Figure $\left.2 \mathrm{~b}\right)$. In all, 2 days of exercise also elevated exon II in all hippocampal regions except for the CA2 in this group (Figure 2c): CA1 (139\%, $\left.\mathrm{F}_{(3,19)}=9.4, \quad p=0.020\right)$; CA3 $\quad(148 \%$, $\left.\mathrm{F}_{(3,19)}=23.53, \quad p<0.001\right) ; \quad \mathrm{CA} 4 \quad\left(172 \%, \quad \mathrm{~F}_{(3,19)}=11.09\right.$, $p<0.001)$ and DG $\left(158 \%, \mathrm{~F}_{(3,19)}=9.42, p=0.003\right)$, and significantly increased exons III $\left(198 \%, \mathrm{~F}_{(3,19)}=3.48\right.$, $p=0.016)$ and $\operatorname{IV}\left(132 \%, \mathrm{~F}_{(3,19)}=3.56, p=0.019\right)$ in the DG (Figures 2d and e).
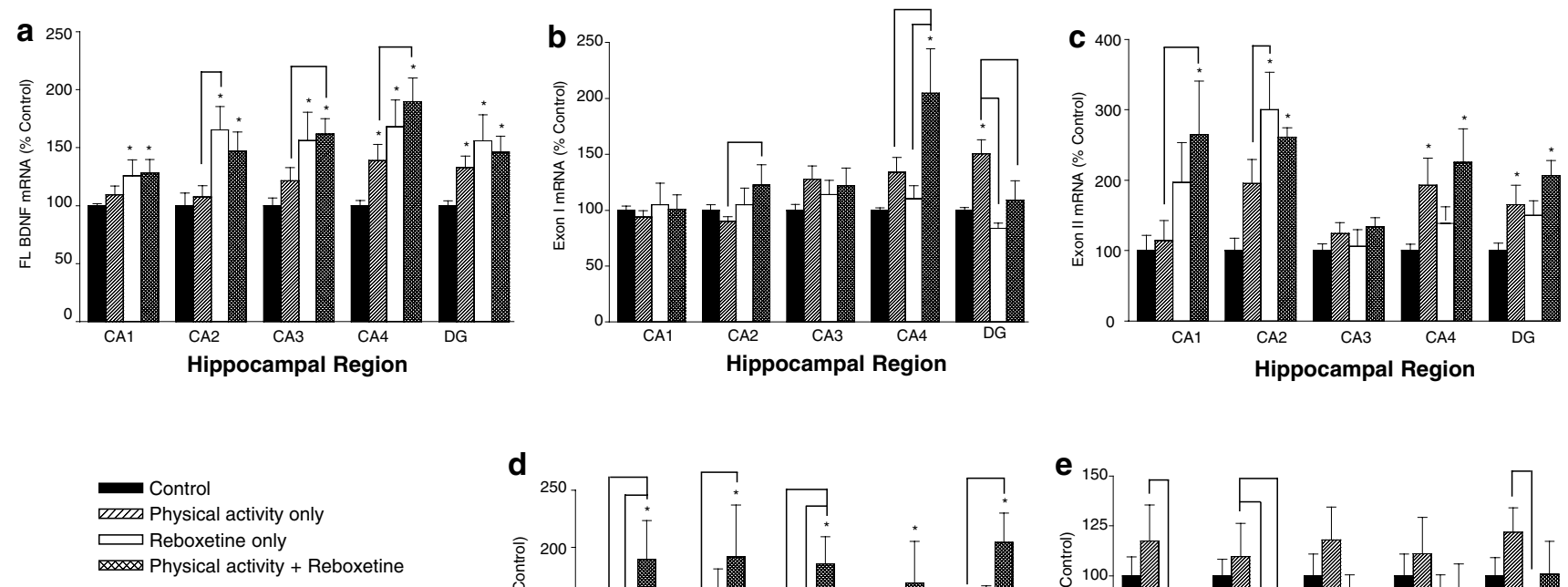

*, Statistically significant from control $\mathrm{P}<0.05$
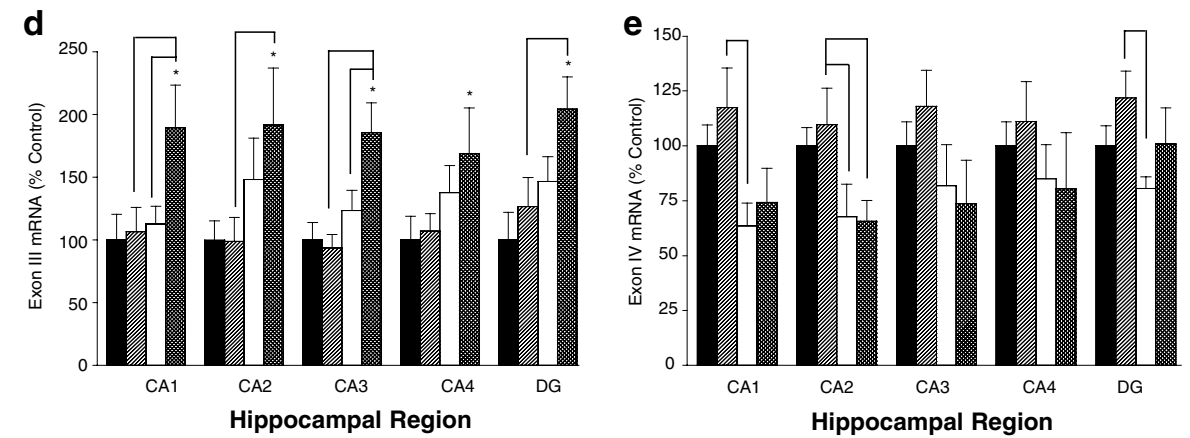

Figure I After 2 days, reboxetine and/or physical activity significantly elevated full-length BDNF (a), exon I (b), exon II (c), exon III (d), and exon IV (e) mRNA levels above those of controls in the indicated hippocampal regions (denoted by asterisks, which indicate statistically significant difference from controls at $p<0.05)$. Statistical significance was determined using one-way ANOVA and subsequent Fisher's PLSD for multiple comparisons. Brackets denote significant differences between the indicated groups $(p<0.05)$. 

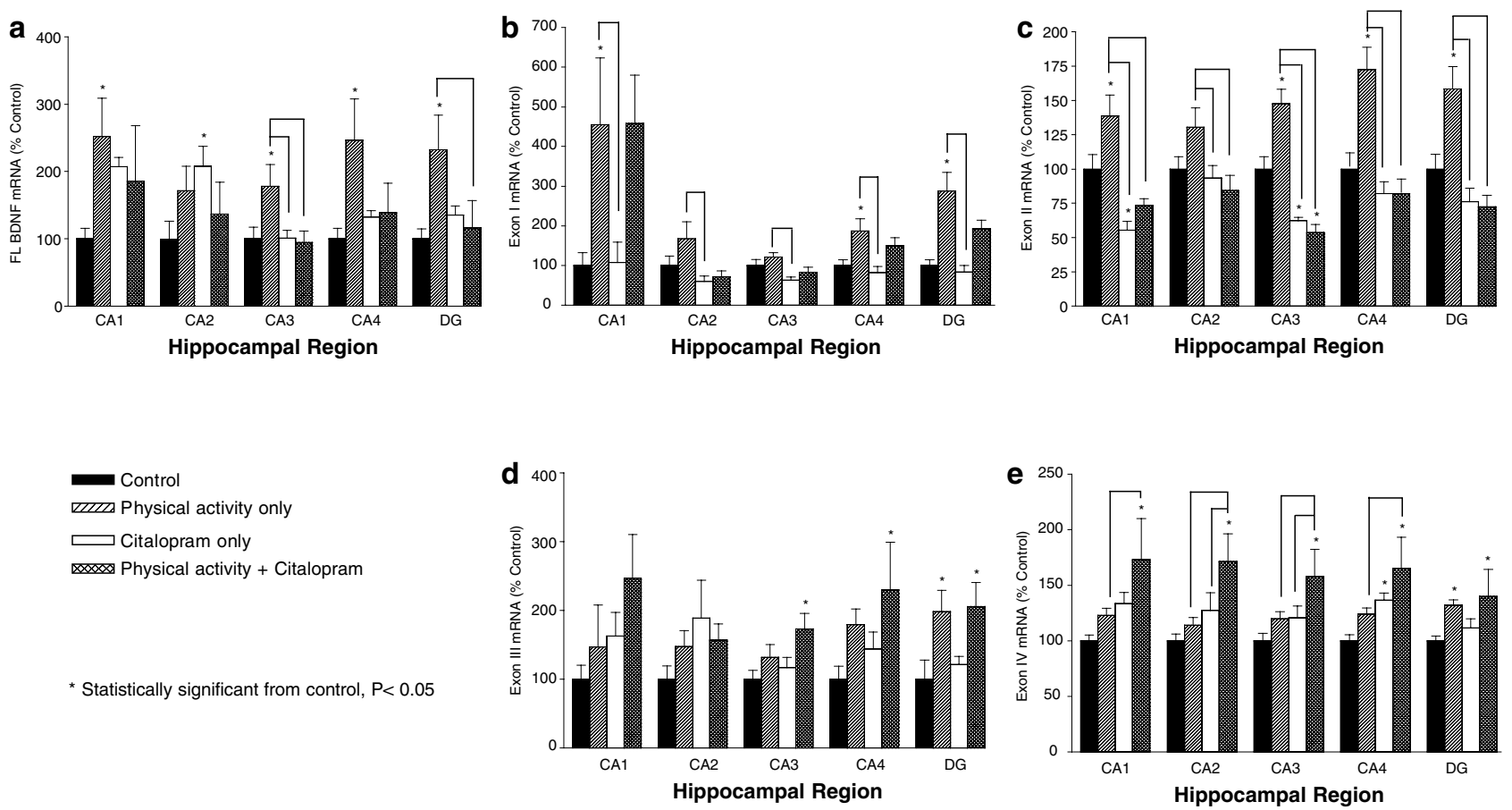

Figure 2 After 2 days, citalopram and/or physical activity significantly elevated full-length BDNF (a), exon I (b), exon II (c), exon III (d), and exon IV (e) mRNA levels above those of controls in the indicated hippocampal regions (denoted by asterisks, which indicate statistically significant difference from controls at $p<0.05$ ). Statistical significance was determined using one-way ANOVA and subsequent Fisher's PLSD for multiple comparisons. Brackets denote significant differences between the indicated groups $(p<0.05)$.

The combination of citalopram-plus-exercise for 2 days had no significant influence on full-length BDNF mRNA levels (Figure 2a). On the other hand, citalopram-plusexercise increased exon III levels in the CA3 $(173 \%$ of control, $\left.\mathrm{F}_{(3,19)}=2.72, p=0.012\right)$, CA4 $\left(230 \%, \mathrm{~F}_{(3,19)}=2.87\right.$, $p=0.012) \quad$ and $\quad$ DG $\left(205 \%, \quad \mathrm{~F}_{(3,19)}=3.48, \quad p=0.025\right.$ Figure 2d), and significantly elevated exon IV levels in all hippocampal regions examined (Figure 2e): CA1 (173\%, $\left.\mathrm{F}_{(3,19)}=4.18, p=0.002\right) ; \operatorname{CA} 2\left(171 \%, \mathrm{~F}_{(3,19)}=5.43, p<0\right.$. $001)$; $\operatorname{CA} 3\left(158 \%, \mathrm{~F}_{(3,19)}=4.161, p=0.002\right)$; CA4 $(165 \%$, $\left.\mathrm{F}_{(3,19)}=5.706, p<0.001\right) ;$ and $\mathrm{DG}\left(140 \%, \mathrm{~F}_{(3,19)}=3.56\right.$, $p=0.013)$.

In this 2-day experiment, all three active groups of rats ran comparably with an average running distance of (mean \pm SEM) $1.08 \pm 0.19$ (saline, physical activity), $0.69 \pm 0.19$ (reboxetine, physical activity), and $0.65 \pm 0.08$ (citalopram, physical activity) kilometers per $24 \mathrm{~h}$ (Figure 7).

\section{One-Week Study}

After 1 week, the effects of reboxetine as a single treatment were not as widespread as those observed at 2 days. Reboxetine treatment upregulated full-length BDNF transcription only in the CA1 at this time point $(130 \%$ of control, $\mathrm{F}_{(3,24)}=6.03, p=0.016$; Figure 3a). Reboxetine led to an increase of exon III mRNA in the CA3 after 1 week $\left(182 \%, \mathrm{~F}_{(3,23)}=3.57, p=0.017\right.$; Figure $\left.3 \mathrm{~d}\right)$, but significantly decreased exon I in the CA1 $\left(58 \%, \mathrm{~F}_{(3,24)}=5.35, p=0.006\right.$; Figure $3 \mathrm{~b}$ ), and exon IV in all subregions examined (Figure 3e): CA1 $\left(36 \%, \mathrm{~F}_{(3,24)}=12.01, p<0.001\right)$; CA2 $\left(28 \%, \mathrm{~F}_{(3,23)}=12.35, p<0.001\right) ; \mathrm{CA} 3\left(42 \%, \mathrm{~F}_{(3,24)}=9.03\right.$, $p<0.001)$; CA4 $\left(40 \%, \mathrm{~F}_{(3,23)}=8.60, p<0.001\right) ;$ and $\mathrm{DG}$ $\left(40 \%, \mathrm{~F}_{(3,24)}=9.75, p<0.001\right)$.

The effects of voluntary exercise on full-length BDNF transcription were very evident after 1 week. Significant increases were observed in all hippocampal subregions except for the CA1 (Figure 3a): CA2 (144\% of control, $\left.\mathrm{F}_{(3,24)}=4.34, \quad p=0.009\right) ; \quad$ CA3 $\quad\left(149 \%, \quad \mathrm{~F}_{(3,24)}=4.87\right.$, $p=0.005) ; \mathrm{CA} 4\left(148 \%, \mathrm{~F}_{(3,24)}=3.32, p=0.016\right) ;$ and $\mathrm{DG}$ $\left(190 \%, \mathrm{~F}_{(3,24)}=3.09, p=0.007\right)$. Exercise also produced a significant increase in exon I mRNA in the DG $(162 \%$, $\mathrm{F}_{(3,24)}=2.53, p=0.045$; Figure $\left.3 b\right)$.

As was observed after 2 days, full-length BDNF mRNA expression was enhanced in most regions examined following the reboxetine/exercise combination for one week (Figure 3a): CA1 ( $145 \%$ of control, $\left.\mathrm{F}_{(3,24)}=6.03, p=0.006\right)$; CA2 $\quad\left(157 \%, \quad \mathrm{~F}_{(3,24)}=4.34, \quad p=0.004\right) ; \quad$ CA3 $\quad(161 \%$, $\left.\mathrm{F}_{(3,24)}=4.87, p=0.004\right) ;$ and CA4 $\left(159 \%, \mathrm{~F}_{(3,24)}=3.32\right.$, $p=0.012$ ). The transcript variant, exon I, was greatly increased by the physical activity/reboxetine combination at 1 week in the CA4 $\left(283 \%, \mathrm{~F}_{(3,24)}=4.09, p=0.004\right.$; Figure $3 \mathrm{~b}$ ), and significantly higher levels were also evident in the DG $\left(173 \%, \mathrm{~F}_{(3,24)}=2.53, p=0.047\right)$. The physical activity/reboxetine combination also enhanced the expression of exon II in the CA3 $\left(158 \%, \mathrm{~F}_{(3,24)}=2.06, p=0.034\right)$; CA4 $\left(185 \%, \mathrm{~F}_{(3,21)}=3.94, p=0.005\right)$; and $\mathrm{DG}(156 \%$, $\mathrm{F}_{(3,24)}=2.26, p=0.041$ (Figure 3c)). Exon III was also significantly elevated by reboxetine-plus-exercise in all hippocampal regions except for the CA2 (Figure 3d): CA1 (185\% from control, $\left.\mathrm{F}_{(3,23)}=4.74, p=0.002\right)$; $\mathrm{CA} 3$ (168\%, $\left.\mathrm{F}_{(3,23)}=3.57, \quad p=0.042\right) ; \quad$ CA4 $\quad\left(181 \%, \quad \mathrm{~F}_{(3,23)}=4.81\right.$, $p=0.003)$; and DG $\left(183 \%, \mathrm{~F}_{(3,23)}=4.31, p=0.003\right)$. Once again, reboxetine-plus-exercise enhanced the expression of 

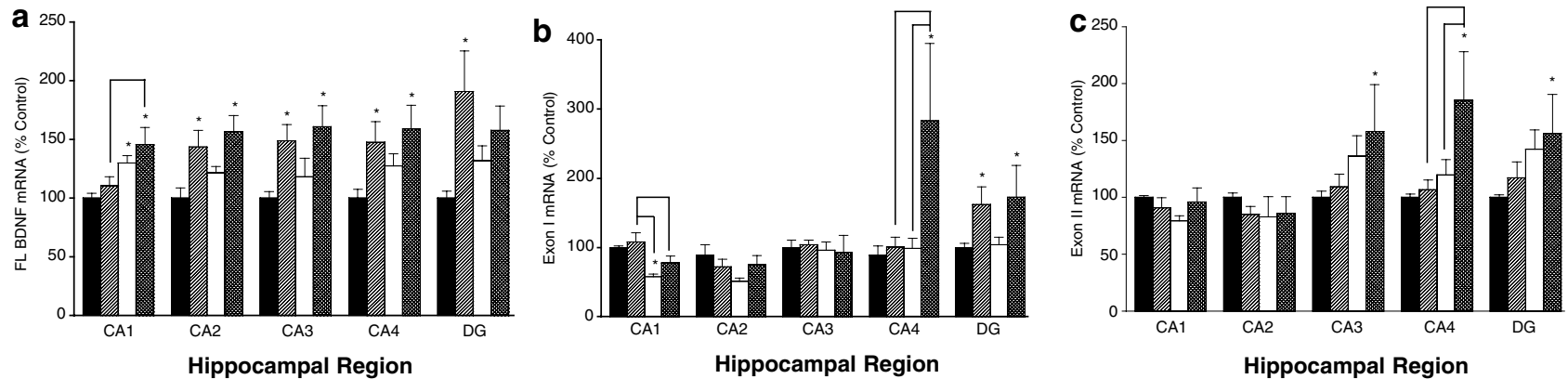

Hippocampal Region

Hippocampal Region
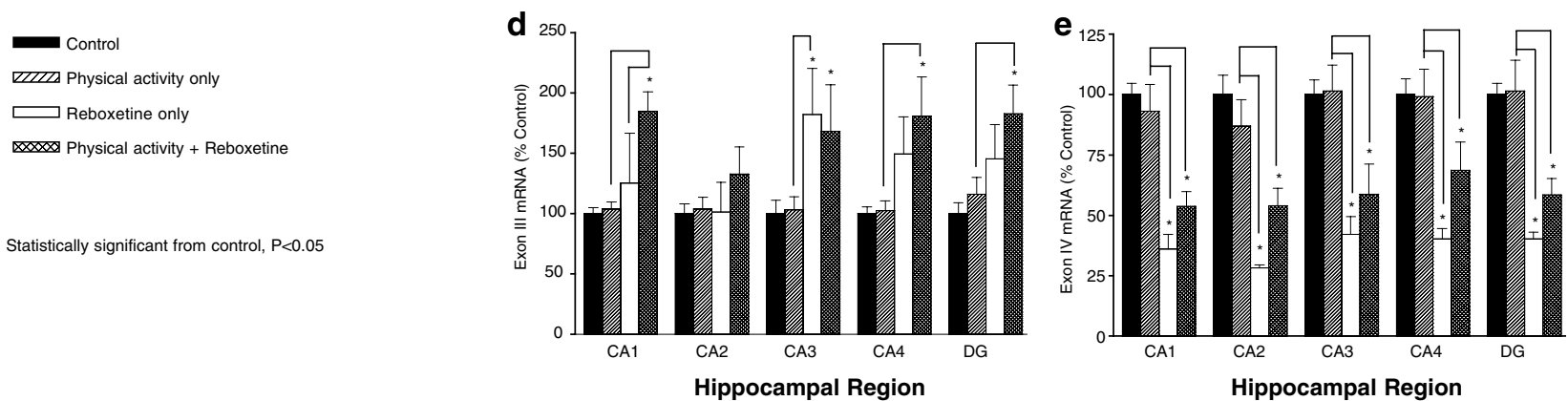

Figure 3 After 7 days, reboxetine and/or physical activity significantly elevated full-length BDNF (a), exon I (b), exon II (c), exon III (d), and exon IV (e) mRNA levels above those of controls in the indicated hippocampal regions (denoted by asterisks, which indicate statistically significant difference from controls at $p<0.05$ ). Statistical significance was determined using one-way ANOVA and subsequent Fisher's PLSD for multiple comparisons. Brackets denote significant differences between the indicated groups $(p<0.05)$.

these transcript variants more than reboxetine alone after 1 week. In striking contrast to these results, exon IV levels were significantly decreased following reboxetine-plusexercise treatments in all hippocampal regions examined (Figure 3e): CA1 (54\% of control, $\mathrm{F}_{(3,24)}=12.01, p=0.001$ ); CA2 $\quad\left(54 \%, \quad \mathrm{~F}_{(3,23)}=12.35, \quad p=0.002\right) ; \quad$ CA3 $\quad(59 \%$, $\left.\mathrm{F}_{(3,24)}=9.03, p=0.007\right) ; \mathrm{CA} 4\left(68 \%, \mathrm{~F}_{(3,23)}=8.6, p=0.028\right)$; and DG $\left(58 \%, \mathrm{~F}_{(3,24)}=9.75, p=0.006\right)$.

In all, 1 week of treatment with citalopram had no effect on full-length BDNF mRNA levels, nor did it significantly affect the levels of any transcript variants (Figures $4 \mathrm{a}-\mathrm{e}$ ). Exercise alone enhanced full-length BDNF mRNA levels in the CA3 $\left(152 \%\right.$ of control, $\left.\mathrm{F}_{(3,23)}=9.79, p=0.002\right)$ and CA4 $\left(151 \%, \mathrm{~F}_{(3,23)}=7.85, p=0.002\right)$. Exercise also significantly increased exon I levels in the CA4 $\left(142 \%, \mathrm{~F}_{(3,23)}=8.35\right.$, $p=0.024) \quad$ and $\quad$ DG $\quad\left(178 \%, \quad \mathrm{~F}_{(3,23)}=9.36, \quad p=0.008\right.$; Figure 4b), and exon II levels in the CA4 (127\%, $\mathrm{F}_{(3,23)}=4.57, p=0.034$; Figure $\left.4 \mathrm{c}\right)$. Conversely, exon IV levels were significantly decreased in all hippocampal regions by one week of exercise in this group: CA1 $(56 \%$ of control, $\left.\mathrm{F}_{(3,23)}=5.56, p=0.001\right)$; $\mathrm{CA} 2\left(48 \%, \mathrm{~F}_{(3,23)}=4.92\right.$, $p=0.001)$; CA3 $\left(50 \%, \mathrm{~F}_{(3,23)}=6.91, p<0.001\right)$; CA4 $(57 \%$, $\left.\mathrm{F}_{(3,23)}=3.73, \quad p=0.004\right) ; \quad$ and $\mathrm{DG}\left(51 \%, \quad \mathrm{~F}_{(3,23)}=4.98\right.$, $p=0.001$; Figure $4 \mathrm{e})$.

When citalopram was combined with exercise for 1 week, full-length BDNF levels were significantly increased in the CA2 $\left(188 \%\right.$ of control, $F_{(3,23)}=2.39, p=0.029$; Figure $\left.4 a\right)$, and exon I levels were elevated in the CA4 (182\%, $\left.\mathrm{F}_{(3,23)}=8.35, p<0.001\right)$ and DG $\left(219 \%, \mathrm{~F}_{(3,23)}=9.36\right.$, $p<0.001$; Figure $4 \mathrm{~b}$ ). This combination treatment had no significant effect on exon II or III (Figures $4 \mathrm{c}$ and d). Exon IV levels were significantly decreased in the CA2 $(67 \%$,
$\left.\mathrm{F}_{(3,23)}=4.92, p=0.024\right), \mathrm{CA} 3\left(70 \%, \mathrm{~F}_{(3,23)}=6.91, p=0.015\right)$, and DG $\left(71 \%, \mathrm{~F}_{(3,23)}=4.98, p=0.038\right.$; Figure $\left.4 \mathrm{e}\right)$.

There was no significant difference in average running distance between the three groups of animals: (mean \pm SEM) $2.30 \pm 0.31$ (saline, physical activity), $1.35 \pm 0.43$ (reboxetine, physical activity), and $1.27 \pm 0.211$ (citalopram, physical activity) kilometers per $24 \mathrm{~h}$ (Figure 7 ).

\section{Fourteen-Day Study}

After 14 days of treatment, reboxetine no longer influenced full-length BDNF mRNA levels, but did increase exon IV levels in the CA2, CA3, and CA4 (Figure 5e): CA2 (138\% of control, $\left.\mathrm{F}_{(3,23)}=2.32, . p=0.037\right)$; CA3 $\left(140 \%, \mathrm{~F}_{(3,23)}=2.26\right.$, $p=0.031)$; and CA4 $\left(141 \%, \mathrm{~F}_{(3,23)}=2.55, p=0.049\right)$. Physical exercise as a single treatment for 14 days increased only exon II in the CA4 $\left(128 \%, \mathrm{~F}_{(3,20)}=11.32, p=0.011\right.$; Figure $5 \mathrm{c}$ ). On the other hand, the combination of reboxetine-plus-exercise for this time interval led to significant increases in full-length BDNF mRNA in the CA3, CA4, and DG (Figure 5a): CA3 $\left(149 \%, \mathrm{~F}_{(3,21)}=2.76\right.$, $p=0.040)$; CA4 $\left(230 \%, \mathrm{~F}_{(3,21)}=5.05, p=0.003\right)$; and $\mathrm{DG}$ $\left(154 \%, \mathrm{~F}_{(3.21)}=5.77, p=0.010\right)$. Also, it should be noted that reboxetine-plus-exercise enhanced the levels of BDNF mRNA significantly over that of the exercise-only group in all regions except in the CA1. This combination treatment also led to striking increases in exon $\mathrm{I}$ in several hippocampal regions (Figure 5b): CA1 (269\%, $\left.\mathrm{F}_{(3,21)}=1.88, \quad p=0.038\right) ; \quad \mathrm{CA} 3 \quad\left(212 \%, \quad \mathrm{~F}_{(3,21)}=5.84\right.$, $p=0.003)$; CA4 $\left(155 \%, \mathrm{~F}_{(3,21)}=3.31, p=0.048\right)$; and $\mathrm{DG}$ $\left(278 \%, \mathrm{~F}_{(3,21)}=10.1, p<0.001\right)$. Significant increases were also observed for exon II in the CA3 $\left(125 \%, \mathrm{~F}_{(3,20)}=5.02\right.$, 

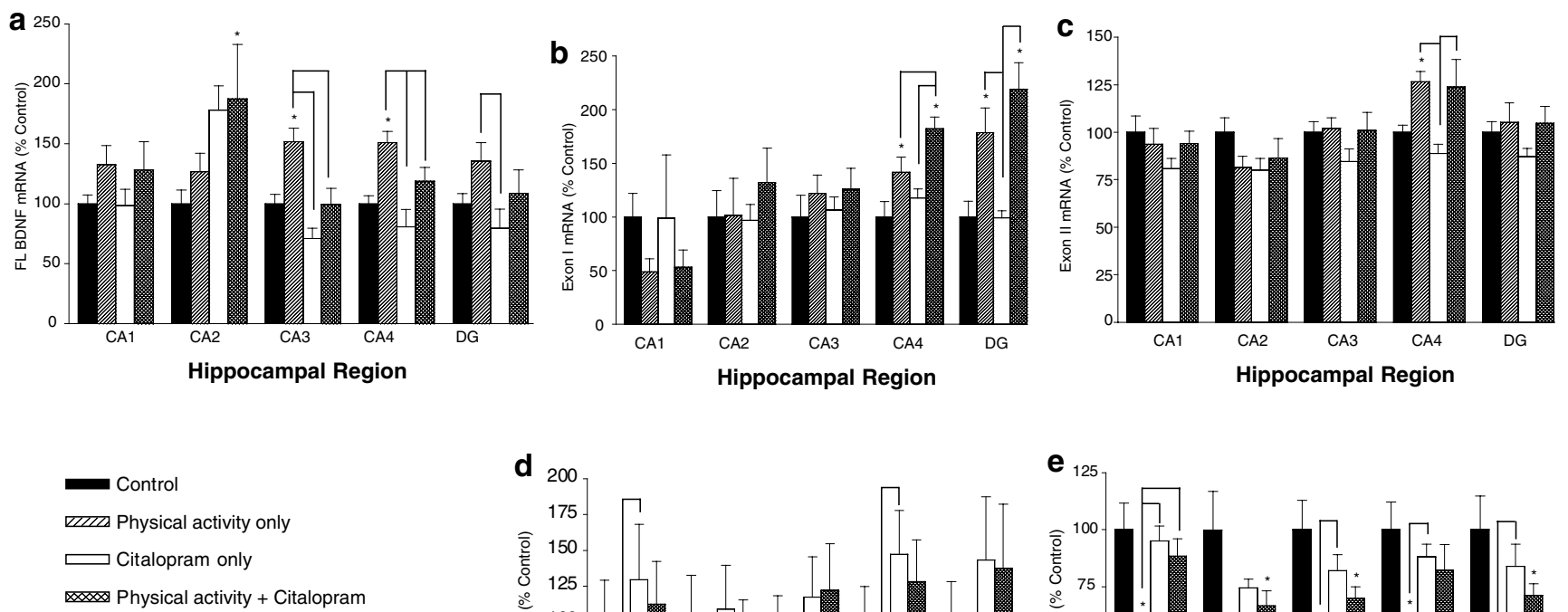

*, Statistically significant from control, $\mathrm{P}<0.05$
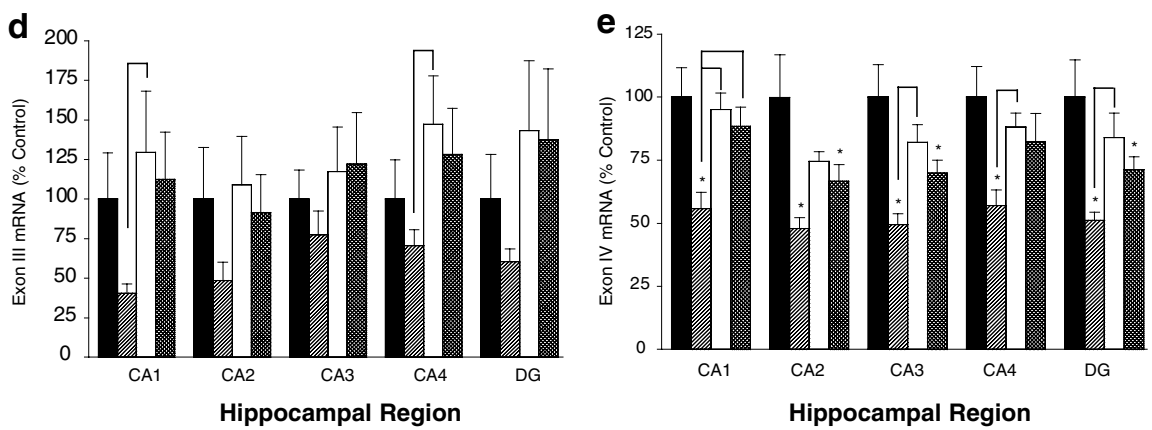

Figure 4 After 7 days, citalopram and/or physical activity significantly elevated full-length BDNF (a), exon I (b), exon II (c), exon III (d), and exon IV (e) mRNA levels above those of controls in the indicated hippocampal regions (denoted by asterisks, which indicate statistically significant difference from controls at $p<0.05$ ). Statistical significance was determined using one-way ANOVA and subsequent Fisher's PLSD for multiple comparisons. Brackets denote significant differences between the indicated groups $(p<0.05)$.

$p=0.032)$ and CA4 (147\%, $\mathrm{F}_{(3,20)}=11.32, \quad p<0.001$ Figure 5c), and for exon IV in the CA4 (147\%, $\left.\mathrm{F}_{(3,23)}=2.55, \quad p=0.019\right)$ and $\mathrm{DG}\left(138 \%, \mathrm{~F}_{(3,23)}=2.36\right.$, $p=0.021$; Figure 5e).

Citalopram alone did not increase full-length BDNF transcription relative to controls in any hippocampal region examined after 2 weeks of treatment. However, as was observed with reboxetine (above), the exon IV transcript variant was elevated in several hippocampal regions (Figure 6e), including CA1 (166\% of control, $\mathrm{F}_{(3,23)}=3.74$ $p=0.006)$, CA3 $\left(156 \%, \mathrm{~F}_{(3,23)}=4.35, p=0.012\right)$, CA4 $(178 \%$, $\left.\mathrm{F}_{(3,23)}=8.82, p<0.001\right)$, and $\mathrm{DG}\left(154 \%, \quad \mathrm{~F}_{(3,23)}=7.84\right.$, $p=0.001)$. Similar to the results noted above, exercise alone for 2 weeks enhanced full-length BDNF (136\% of control, $\mathrm{F}_{(3,24)}=5.12, p=0.035$; Figure 6a) and exon II only in the CA4 $\left(127 \%, \mathrm{~F}_{(3,24)}=4.86, p=0.011\right.$; Figure $\left.6 \mathrm{c}\right)$. The combination of citalopram plus exercise, on the other hand, led to significant elevations in full-length BDNF mRNA in the CA4 and DG (Figure 6a): CA4 (158\% of control, $\left.\mathrm{F}_{(3,21)}=5.12, p=0.002\right)$; DG $\left(134 \%, \mathrm{~F}_{(3,21)}=8.41, p=0.008\right)$, and increases in several transcript variants. Exon I was elevated by citalopram-plus-exercise in the CA1 and DG (Figure $6 \mathrm{~b})$ : CA1 (280\% of control, $\left.\mathrm{F}_{(3,21)}=3.81, p=0.005\right)$; DG $\left(225 \%, \mathrm{~F}_{(3,21)}=8.51, p=0.002\right)$. Exon II was increased in the CA4 $\left(125 \%, \mathrm{~F}_{(3,20)}=4.86, p=0.016\right.$; Figure $\left.6 \mathrm{c}\right)$, and exon IV was elevated in the CA3 $\left(157 \%, \mathrm{~F}_{(3,23)}=4.35\right.$, $p=0.007)$, CA4 $\left(180 \%, \mathrm{~F}_{(3,23)}=8.82, p<0.001\right)$, and $\mathrm{DG}$ $\left(160 \%, \mathrm{~F}_{(3,23)}=7.84, p<0.001\right.$; Figure $\left.6 \mathrm{e}\right)$.

Rats allowed access to exercise during this 2-week study ran an average of (mean \pm SEM) $0.853 \pm 0.20$ (saline, physical activity), $4.32 \pm 0.16$ (reboxetine, physical activity), and $1.99 \pm 0.53$ (citalopram, physical activity) kilometers per $24 \mathrm{~h}$. There was a significant effect of treatment group on average running distance over the entire 14 days $\left(\mathrm{F}_{(2,18)}=26.96, p<.0001\right)$. In addition, two-way ANOVA revealed a significant effect for group $\left(\mathrm{F}_{(2,241)}=97.08\right.$, $p<0.0001)$, time $\left(\mathrm{F}_{(13,241)}=6.30, p<0.0001\right)$, and the interaction between time and treatment group $\left(\mathrm{F}_{(26,241)}=1.97, p=0.0045\right)$. Note that rats treated with reboxetine ran, on average, more than double the citalopram group and 5 times more than animals given saline vehicle (Figure 7 ).

\section{DISCUSSION}

Evidence exists that NE stimulation is important for both exercise- and antidepressant-induced regulation of hippocampal BDNF expression (Garcia et al, 2003; Ivy et al, 2003). Therefore, it is possible that neuronal stimulation via NE may activate a common intracellular pathway for antidepressant medications and exercise, and participate in the additive effects of these two interventions (Russo-Neustadt et al, 2000). Furthermore, many antidepressants stimulate BDNF expression after chronic but not acute treatment (Nibuya et al, 1995; Nibuya et al, 1996), and the addition of exercise accelerates increases in BDNF expression with tranylcypromine treatment (Russo-Neustadt et al, 2000). Therefore, NE stimulation may exert a rapid influence on BDNF expression. Consistent with this idea is our current observation that reboxetine, a highly NE-selective antidepressant (Montgomery, 1999), led to rapid (within 2 days) increases in hippocampal BDNF mRNA. This effect was sustained over 2 weeks when reboxetine was combined with 

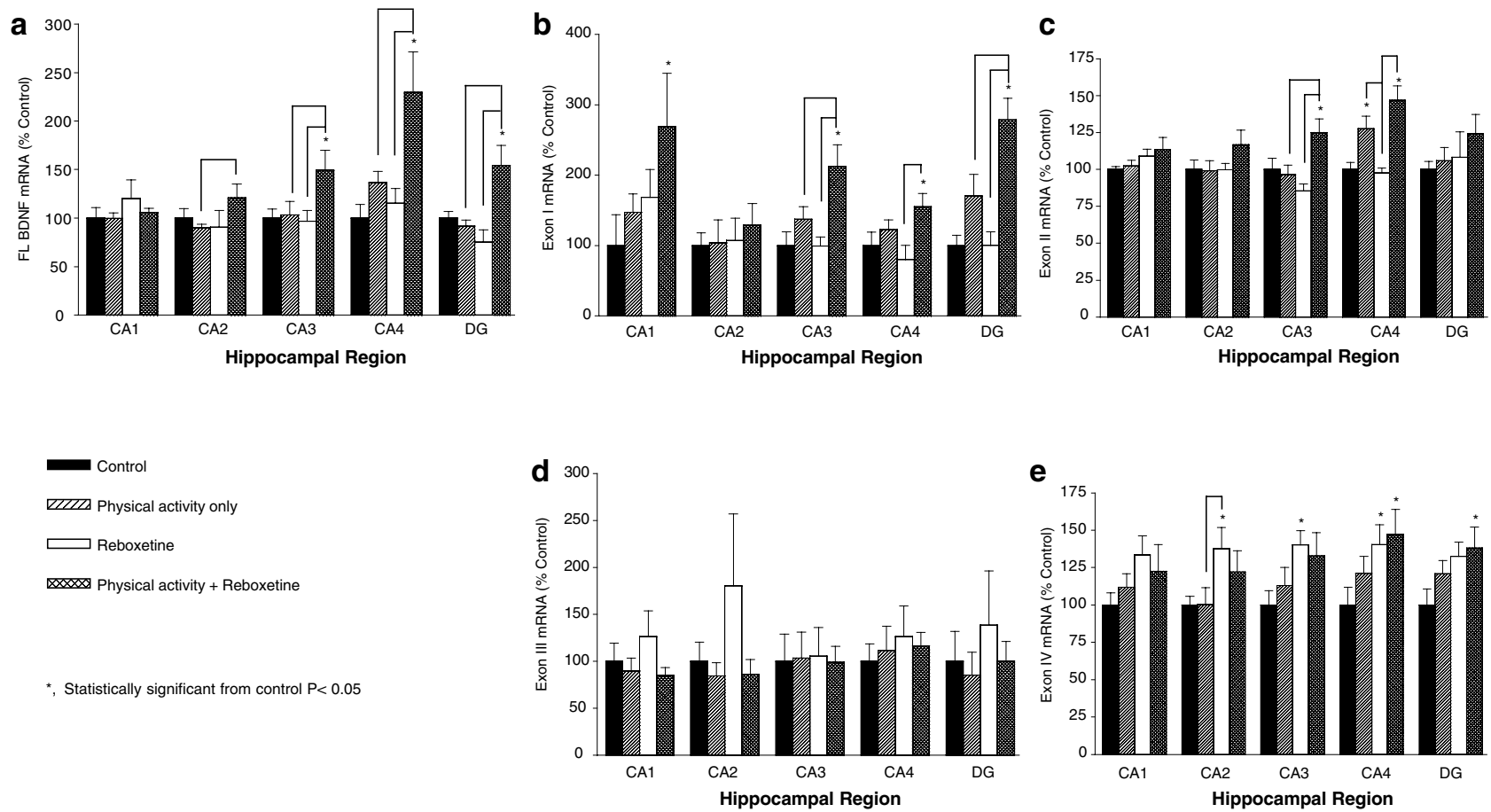

Figure 5 After I 4 days, reboxetine and/or physical activity significantly elevated full-length BDNF (a), exon I (b), exon II (c), exon III (d), and exon IV (e) mRNA levels above those of controls in the indicated hippocampal regions (denoted by asterisks, which indicate statistically significant difference from controls at $p<0.05)$. Statistical significance was determined using one-way ANOVA and subsequent Fisher's PLSD for multiple comparisons. Brackets denote significant differences between the indicated groups $(p<0.05)$.
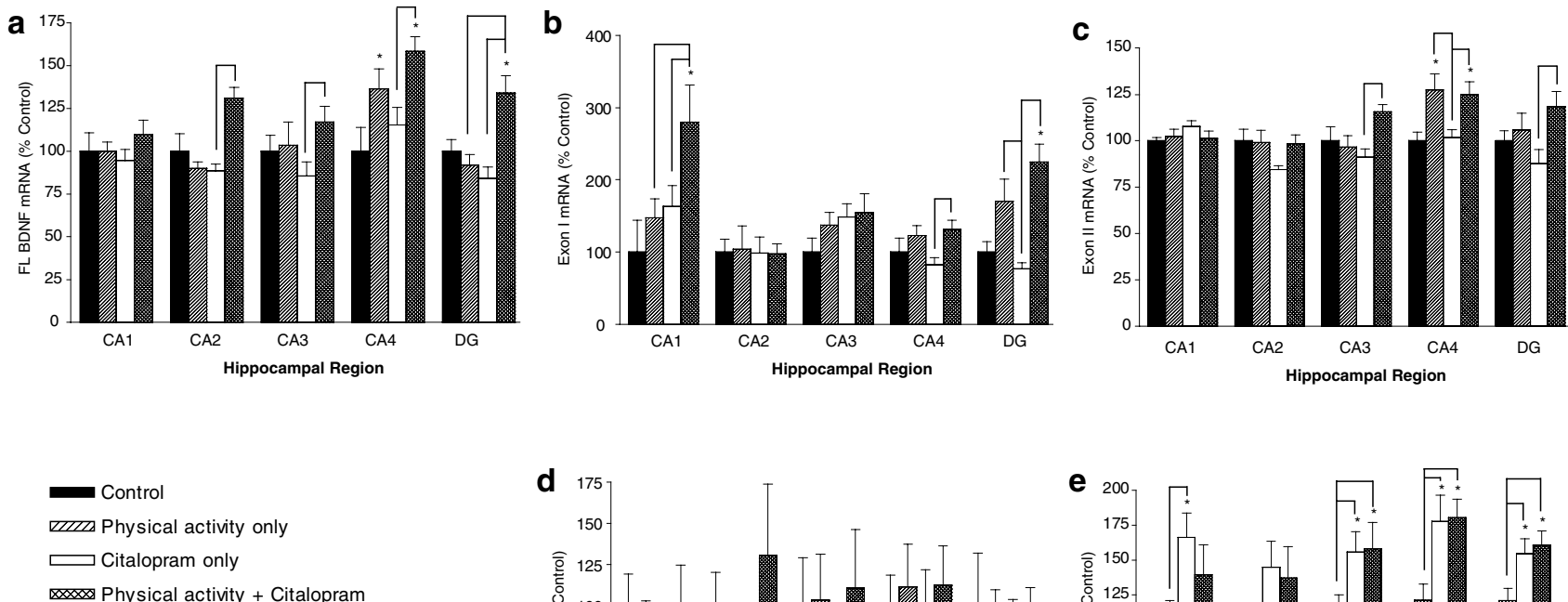

*, Statistically significant from contro $\mathrm{P}<0.05$
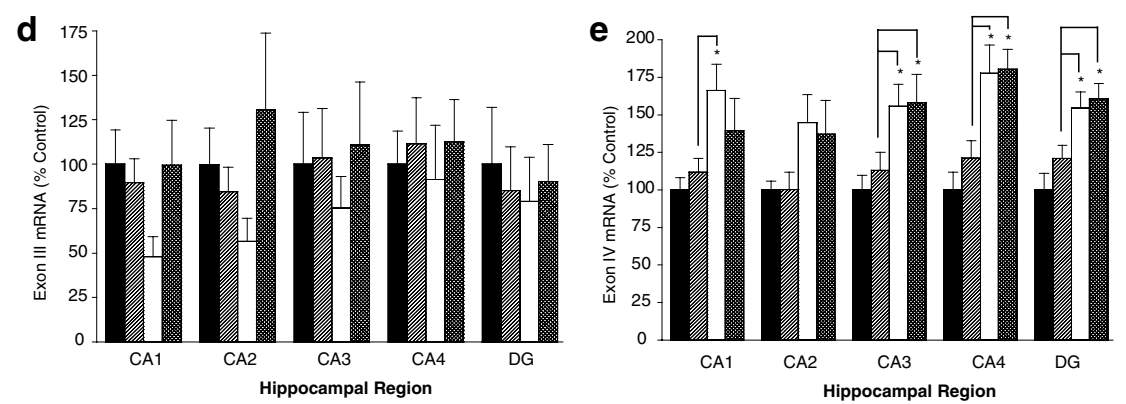

Figure 6 After I4 days, citalopram and/or physical activity significantly elevated full-length BDNF (a), exon I (b), exon II (c), exon III (d), and exon IV (e) mRNA levels above those of controls in the indicated hippocampal regions (denoted by asterisks, which indicate statistically significant difference from controls at $p<0.05)$. Statistical significance was determined using one-way ANOVA and subsequent Fisher's PLSD for multiple comparisons. Brackets denote significant differences between the indicated groups $(p<0.05)$.

exercise. It should be noted, also, that the combination of exercise with reboxetine increased the expression of several BDNF transcript variants that were not influenced by reboxetine alone. The addition of exercise therefore appeared to make the effect of reboxetine on BDNF expression more widespread and long-lasting. Importantly, 

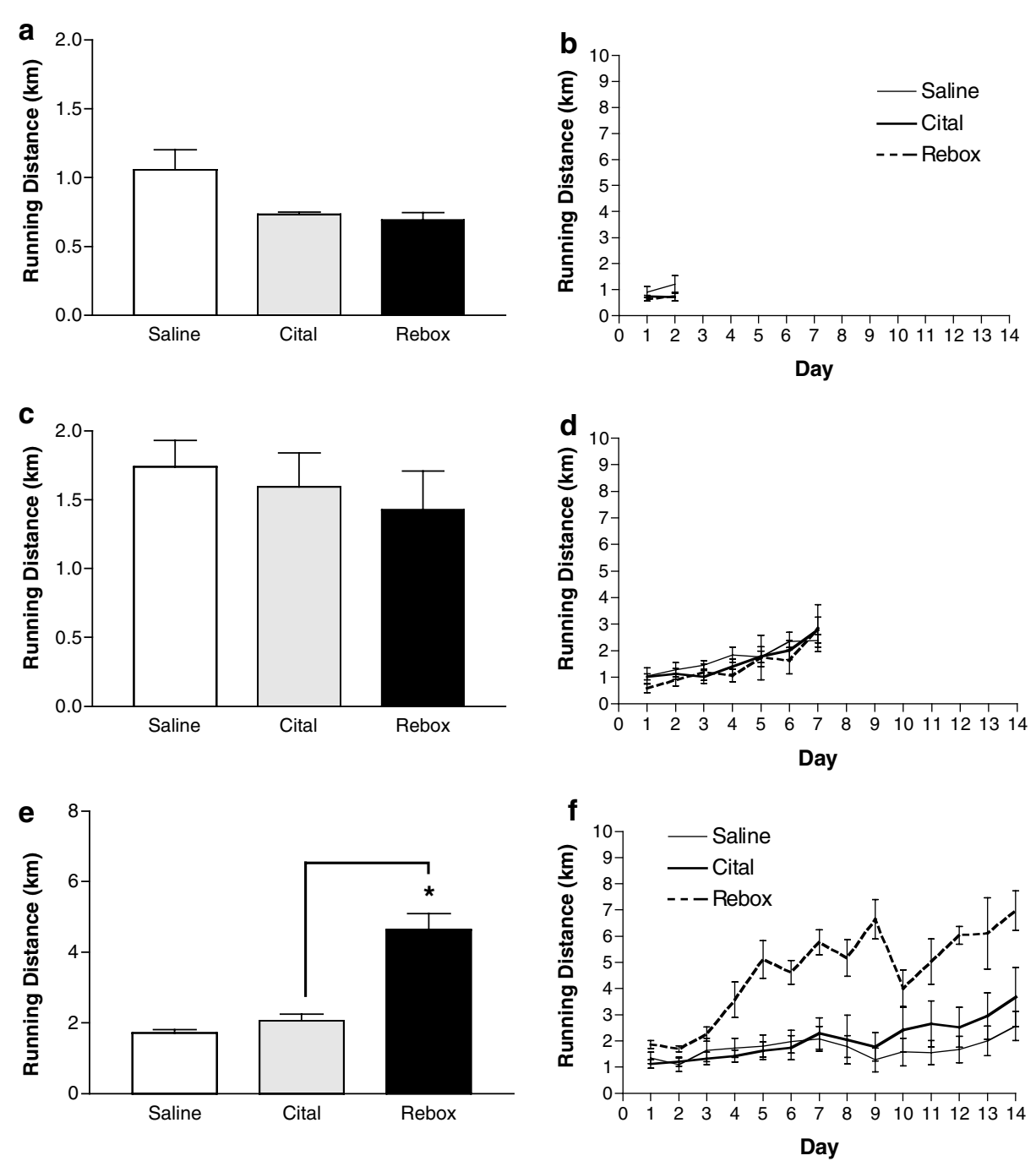

Figure 7 Longer-term treatment with reboxetine had a significant effect on wheel-running activity. Average running distance for each study is shown $(a, c, e)$, and statistically significant differences from saline controls are denoted by asterisks $(p<0.05)$. Statistical significance was determined using one-way ANOVA and subsequent Fisher's PLSD for multiple comparisons. Brackets denote significant differences between the indicated groups $(p<0.05)$. The average running distance over time is also detailed for each study $(b, d, f)$. A two-way ANOVA revealed a significant effect for group $\left(F_{(2,241)}=97.08\right.$, $p<0.000 \mathrm{I})$, time $\left(\mathrm{F}_{(13,24 \mathrm{I})}=6.30, p<0.000 \mathrm{I}\right)$, and the interaction between time and treatment group $\left(F_{(26,24 I)}=1.97, p=0.0045\right)$ for the 14 -day study only (f).

however, long-term reboxetine treatment had an elevating effect on animal activity. Running distance was increased to a significant degree after 14 days of reboxetine treatment (Figure 7). Therefore, the robust increase in BDNF mRNA following the reboxetine/exercise combination at this time interval could be due to increased activity rather than a purely pharmacological effect.

Citalopram, a highly 5-HT-selective monoamine reuptake inhibitor (Sanchez and Hyttel, 1999), led to less consistent and widespread changes in hippocampal BDNF mRNA than reboxetine after short-term treatment. After 2 days, fulllength BDNF mRNA levels were increased in only one hippocampal area, the CA2. Examination of individual transcript variants revealed that citalopram treatment led to a decrease in exon II and an increase in exon IV in several regions. These opposing effects of citalopram on individual subclasses of BDNF mRNA may explain the lack of a net effect on total BDNF mRNA expression in several hippo- campal regions after short-term treatment. After long-term (14 days) treatment, on the other hand, citalopram enhanced total hippocampal BDNF transcription, as well as the expression of three transcript variants (exons I, II, and IV) when combined with physical activity. Citalpram treatment also independently enhanced the expression of exon IV with both short- (2 days) and long-term (14 days) treatment. Evidence suggests that 5-HT-selective antidepressant-induced changes in the expression of neurotrophins (Duman, 1998), as well as alterations in behavior (Detke et al, 1997; Lucki, 1998), require chronic treatment. It is possible, therefore, that treatment with citalopram may require longer intervals in order to influence the expression of most BDNF mRNA isoforms. Nevertheless, citalopram rapidly influenced the expression of the exon IV variant (this was especially widespread when combined with exericse), and this effect was even more evident with chronic (2 weeks) treatment. As was observed with 
reboxetine, the addition of exercise to citalopram therapy led to more widespread and robust changes in the expression of several BDNF mRNA isoforms than treatment with citalopram (or exercise) alone. Examples include the effects of the citalopram/exercise combination on the expression of full-length BDNF, exon I and exon II after 2 weeks of treatment (Figure 5a-c).

It is important to note that, since different modes of administration were used for reboxetine (twice per day dosing i.p.) and citalopram (continuous infusion) during the 2- and 7-day treatment intervals, it is possible that this variation may have influenced the results. Several other investigators have revealed no significant differences in treatment responses to antidepressants and related compounds following these two modes of administration in rats. For example, no variation was evident in clovoxamine- or desipramine-induced downregulation of the $5-\mathrm{HT}_{2}$ receptor in the frontal cortex (Bradford et al, 1987). Additionally, neuronal responsiveness to amytriptyline (Gravel and de Montigny, 1987), antidepressant-induced upregulation of GABA-B binding (Lloyd et al, 1985), and 8-hydroxy-2-(di- $n$ propylamino)-tetralin-induced inhibition of 5-HT in the cortex and hippocampus (Bohmaker et al, 1993) did not vary with the two modes of administration. We investigated a possible variation in nondrug (exercise) responses with the two different control groups (saline administered via osmotic minipump vs i.p. injections). BDNF mRNA changes following exercise were compared using unpaired Student's $t$-tests. These statistical comparisons revealed significantly higher exercise-associated total BDNF levels in the hippocampal CA1 and DG with continuous infusion of saline compared to b.i.d. injection during the 2-day study. No differences were evident following the 7-day study. Similarly, exon I levels were significantly higher in the CA1, CA2, and DG following continuous infusion (2 days only). On the other hand, exon III levels were significantly higher in several regions (CA1, CA4, and DG) following i.p. injection as compared to continuous infusion (at 7 days only). Exon IV levels were also relatively elevated in all hippocampal regions following 7 days of i.p. injection. These results suggest that full-length BDNF and exon I responses might possibly be predisposed to a higher level with continuous infusion (citalopram administration) during the 2-day study, and that responses to exons III and IV may be greater with i.p. injection (reboxetine) after 7 days. In our experiments, full-length BDNF and exon I responses to 2 days of treatment were higher following i.p. reboxetine than continuously infused citalopram (Figures 1 and 2), and exon IV responses to i.p. reboxetine were lower than continuously infused citalopram after 1 week of treatment (Figures 3 and 4). Therefore, it could be kept in mind that some changes evident in our results may be slightly attenuated due to the different modes of administration for these two antidepressants.

Exercise leads to activation of several CNS neurotransmitter systems, including the NE, 5-HT, and glutamatergic systems (Dey et al, 1992; Dunn et al, 1996; Dishman et al, 2000; Molteni et al, 2002). Recent evidence has indicated that NE activation is essential for the BDNF expressionenhancing effects of exercise (Garcia et al, 2003), and that both NE and 5-HT stimulation are important for the elevation of BDNF mRNA occurring with tranylcypromine treatment (Ivy et al, 2003). Previous evidence exists that beneficial behavioral outcomes can result from exercise. In addition to enhancing hippocampal BDNF expression, longterm voluntary exercise has been shown to have anxiolytic effects in animals (Dishman, 1997), and antidepressant effects in humans (Morgan, 1985; Labbe et al, 1988; Hill et al, 1993). Chronic exercise has been shown to decrease depressive-like (learned helpless) behaviors in rat models, and alter the activity of serotonergic neurons in the dorsal raphe nucleus (Greenwood et al, 2003). Enhanced cognitive performance has been shown to result from exercise (Samorajski et al, 1985; Fordyce and Wehner, 1993). In addition, recent evidence indicates that physically active rodents demonstrate enhanced hippocampal neurogenesis (van Praag et al, 1999) and possess some resistance to the damaging effects of acute stressor exposure or brain injury. For example, exercise has been shown to enhance the expression of the heat shock protein HSP72 in the hippocampus and other brain areas (Campisi et al, 2003). In addition, laboratory rodents submitted to treadmill running near the time of experimental hippocampal lesions maintain intact spatial memory function (Carro et al, 2001).

The examination of individual transcript variants of BDNF revealed distinct patterns of expression following treatment with each of the different antidepressants. As might be expected, strong increases in the exon I variant were evident with short-term activity and activity/antidepressant treatments that were sustained with chronic combination therapy. Robust and long-lasting increases in this transcript have been reported following two other activating antidepressant treatments, tranylcypromine (Russo-Neustadt et al, 2000) and electroconvulsive stimulation (Dias et al, 2003). The exon II BDNF transcript variant, which has been shown to increase in the hippocampus following short-term exercise (Russo-Neustadt et al, 2000), was also increased following 2 days of reboxetine and reboxetine/activity, but was decreased with short-term citalopram. Significant increases in exon II expression were also evident following antidepressant/exercise combinations for 7 or 14 days. Consistent with an immediate early gene mode of expression (Lauterborn et al, 1996), hippocampal levels of the exon III variant were enhanced following shortterm treatment only; no changes were evident following chronic treatment (14 days). It should be noted that shortterm exercise/antidepressant combinations (using both reboxetine and citalopram) were particularly effective in elevating the expression of exon III (Figures $1 \mathrm{~d}, 2 \mathrm{~d}$ and $3 \mathrm{~d}$ ). The expression of exon IV appeared to be especially responsive to short-term citalopram treatment, which increased this variant in several hippocampal regions after 2 days. Surprisingly, subchronic (7 days) treatment with both antidepressants decreased expression of exon IV below baseline. After chronic (14 days) treatment, both antidepressants led to increases in exon IV in several hippocampal areas, with the most widespread effects due to citalopram. When taking a general overview of the results, it appears that subchronic (7 days) treatment produced less positive results than either short-term (2 days) or chronic (14 days) treatment. It is possible that the 7-day time interval may occur after the time of optimal $\mathrm{NE}$ activation and before the time of an optimal 5-HTinduced stimulus. On a similar vein, it was recently reported 
that shorter-term treatment with some antidepressant agents led to decreases in some exon-specific BDNF transcripts (Dias et al, 2003). As noted earlier, all of the transcript variants of BDNF studied (containing exons I, II, III, or IV) are directed through distinct promoters. Therefore, distinct intracellular signaling pathways are likely activated in order to enhance the expression of each exon. Each mRNA variant is translated into the identical BDNF protein, as none of the exons are contained within the coding region for BDNF. The function of interventiondependent, regionally and temporally distinct patterns of expression of these transcripts are therefore not clear. It is possible that they may reflect differential peri-transcriptional regulation, such as mRNA stability or localization, and therefore may lead to distinct effects upon neuronal growth and survival within the brain. Several investigators report region-specific and intervention-specific patterns of BDNF exon expression within the hippocampus, hypothalamus, and cerebral cortex. For example, immobilization stress rapidly increases hippocampal exon III expression, elevates exons I and II over a longer time course, and decreases exon IV (Marmigere et al, 2003). Osmotic stress elevates exon I in the hypothalamic supraoptic nucleus, and leads to a dramatic increase in exon II in the paraventricular nucleus (Aliaga et al, 2002).

It is important to note that hippocampal BDNF gene expression responses and subsequent protein transcription follow different time courses (Nawa et al, 1995). Therefore, it cannot be assumed that rapid changes in BDNF mRNA expression will correlate with parallel changes in hippocampal BDNF concentration. In our own laboratory, we have observed that BDNF protein increases at a later time than mRNA following exercise and exercise/antidepressant interventions. BDNF mRNA showed significant changes in as little as 2 days, but protein approached a significant increase after 7 days of an exercise/tranylcypromine combination, and was strikingly elevated after 14 days following exercise or exercise/tranylcypromine (unpublished data).

In conclusion, our results support a growing body of evidence that exercise augments antidepressant-associated increases in the expression of the hippocampal BDNF gene. Several transcript variants of BDNF that were not significantly influenced by a particular antidepressant were elevated when that antidepressant was combined with ongoing voluntary physical activity. In a very general sense, the impact of the NE-selective agent, reboxetine on hippocampal BDNF expression appeared to be rapid, but not long-lasting without concomitant exercise. The 5-HTselective agent, citalopram, on the other hand, appeared to require more chronic treatment before significant effects on most BDNF transcripts became evident. It appears that exercise served to 'fill in the gap' for both of these; extending the time of treatment effectiveness and expanding the range of $\mathrm{BDNF}$ transcript variants elevated by either treatment. In several recent clinical trials, reboxetine was assessed to have equal total efficacy compared to 5-HTselective antidepressants such as citalopram and fluoxetine (eg comparable scores on the Hamilton Depression Inventory; Andreoli et al, 1999), but was found to be superior for enhanced social functioning and activation (Massana, 1998; Montgomery and Schatzberg, 1998; Tse and
Bond, 2002). This may be consistent with the enhanced activation observed following reboxetine treatment in the rat forced swim test (Page et al, 2003), and the effects we observed on wheel running activity following long-term reboxetine (Figure 7). To our knowledge, no formal studies have compared treatment onset for reboxetine and citalopram or other 5-HT-selective reuptake inhibitors.

\section{ACKNOWLEDGEMENTS}

This work was supported by PHS Grant MH-59776 and NARSAD Young Investigator Award to ARN, Minority Biomedical Research Support Program to CG, and Arnold and Mabel Beckman Scholars Program to ASI. We thank Irwin Lucki, $\mathrm{PhD}$ for valuable comments during the preparation of this manuscript. We also thank Pharmacia Corp. for providing reboxetine for this study, and Lundbeck for providing citalopram.

\section{REFERENCES}

Aliaga E, Arancibia S, Givalois L, Tapia-Arancibia L (2002). Osmotic stress increases brain-derived neurotrophic factor messenger RNA expression in the hypothalamic supraoptic nucleus with differential regulation of its transcripts. Relation to arginine-vasopressin content. Neuroscience 112: 841-850.

Andreoli V, Carbognin G, Abati A, Vantini G (1999). Reboxetine in the treatment of depression in the elderly: pilot study. J Geriatr Psychiatry Neurol 12: 206-210.

Berchtold NC, Oliff HS, Isackson P, Cotman CW (1997). Brainderived neurotrophic factor (BDNF) shows a circadian pattern of expression in the hippocampal formation. Soc Neurosic Abstr 23: 46.

Bohmaker K, Eison AS, Yocca FD, Meller E (1993). Comparative effects of chronic 8-OH-DPAT, gepirone and ipsapirone treatment on the sensitivity of somatodendritic 5-HT1A autoreceptors. Neuropharmacology 32: 527-534.

Bradford LD, Tulp MT, Schipper J (1987). Biochemical effects in rats after acute and long-term treatment with clovoxamine. Arch Int Pharmacodyn Ther 287: 188-202.

Campisi J, Leem TH, Greenwood BN, Hansen MK, Moraska A, Higgins K, Smith TP, Fleshner M et al (2003). Habitual physical activity facilitates stress-induced HSP72 induction in brain, peripheral, and immune tissues. Am J Physiol 284: R520-R530.

Carro E, Trejo JL, Busiguiana S, Torres-Aleman I et al (2001). Circulating insulin-like growth factor I mediates the protective effects of physical exercise against brain insults of different etiology and anatomy. J Neurosci 21: 5678-5684.

Cryan JF, Markou A, Lucki I (2002). Assessing antidepressant activity in rodents: recent developments and future needs. Trends Pharmacol Sci 23: 238-245.

Detke MJ, Johnson J, Lucki I (1997). Acute and chronic antidepressant drug treatment in the rat forced swimming test model of depression. Exp Clin Psychopharmacol 5: 107-112.

Dey S, Singh RH, Dey PK (1992). Exercise training: significance of regional alterations in serotonin metabolism of rat brain in relation to antidepressant effect of exercise. Physiol Behav 52: 1095-1099.

Dias BG, Banerjee SB, Duman RS, Vaidya VA (2003). Differential regulation of brain derived neurotrophic factor transcripts by antidepressant treatments in the adult rat brain. Neuropharmacology 45: 553-563.

Dishman RK (1997). Brain monoamines, exercise, and behavioral stress: animal models. Med Sci Sports Exerc 29: 63-74.

Dishman RK, Renner KJ, White-Welkley JE, Burke KA, Bunnell BN (2000). Treadmill exercise training augments brain norepi- 
nephrine response to familiar and novel stress. Brain Res Bull 52: 337-342.

Duman RS (1998). Novel therapeutic approaches beyond the serotonin receptor. Biol Psychiatry 44: 324-335.

Duman RS, Heninger GR, Nestler EJ (1997). A molecular and cellular theory of depression. Arch Gen Psychiatry 54: 597-606.

Dunn AL, Reigle TG, Youngstedt SD, Armstrong RB, Dishman RK (1996). Brain norepinephrine and metabolites after treadmill training and wheel running in rats. Med Sci Sports Exerc 28: 204-209.

Fordyce DE, Wehner JM (1993). Physical activity enhances spatial learning performance with an associated alteration in hippocampal protein kinase $\mathrm{C}$ activity in $\mathrm{C} 57 \mathrm{BL} / 6$ and $\mathrm{DBA} / 2$ mice. Brain Res 619: 111-119.

Garcia C, Chen MJ, Garza AA, Cotman CW, Russo-Neustadt A (2003). The influence of specific noradrenergic and serotonergic lesions on the expression of hippocampal brain-derived neurotrophic factor transcripts following voluntary physical activity. Neuroscience 119: 721-732.

Gravel P, de Montigny C (1987). Noradrenergic denervation prevents sensitization of rat forebrain neurons to serotonin by tricyclic antidepressant treatment. Synapse 1: 233-239.

Greenwood BN, Foley TE, Day HE, Campisi J, Hammack SH, Campeau S et al (2003). Freewheel running prevents learned helplessness/behavioral depression: role of dorsal raphe serotonergic neurons. J Neurosci 23: 2889-2898.

Hill RD, Storandt M, Malley M (1993). The impact of long-term exercise training on psychological function in older adults. J Gerontol 48: 12-17.

Ivy AS, Rodriguez FG, Garcia C, Chen MJ, Russo-Neustadt AA (2003). Noradrenergic and serotonergic blockade inhibits BDNF mRNA activation following exercise and antidepressant. Pharmacol Biochem Behav 75: 81-88.

Kuroda Y, McEwen BS (1998). Effect of chronic restraint stress and tianeptine on growth factors, growth-associated protein-43 and microtubule-associated protein 2 mRNA expression in the rat hippocampus. Brain Res Mol Brain Res 59: 35-39.

Labbe EE, Welsh MC, Delaney D (1988). Effects of consistent aerobic exercise on the psychological functioning of women. Percept Mot Skills 67: 919-925.

Lauterborn JC, Rivera S, Stinis CT, Hayes VY, Isackson PJ, Gall CM (1996). Differential effects of protein synthesis inhibition on the activity-dependent expression of BDNF transcripts: evidence for immediate-early gene responses from specific promoters. J Neurosci 16: 7428-7436.

Lloyd KG, Thuret F, Pilc A (1985). Upregulation of gammaaminobutyric acid (GABA) B binding sites in rat frontal cortex: a common action of repeated administration of different classes of antidepressants and electroshock. J Pharmacol Exp Ther 235: 191-199.

Lucki I (1998). The spectrum of behaviors influenced by serotonin. Biol Psychiatry 44: 151-162.

Marmigere F, Givalois L, Rage F, Arancibia S, Tapia-Arancibia L (2003). Rapid induction of BDNF expression in the hippocampus during immobilization stress challenge in adult rats. Hippocampus 13: 646-655.

Massana J (1998). Reboxetine versus fluoxetine: an overview of efficacy and tolerability. J Clin Psychiatry 59(Suppl 14): 8-10.

Molteni R, Ying Z, Gomez-Pinilla F (2002). Differential effects of acute and chronic exercise on plasticity-related genes in the rat hippocampus revealed by microarray. Eur J Neurosci 16: 1107-1116.
Montgomery SA (1999). Predicting response: noradrenaline reuptake inhibition. Int Clin Psychopharmacol 14(Suppl 1): S21-S26.

Montgomery SA, Schatzberg AF (1998). Introduction. Reboxetine: a new selective antidepressant for the treatment of depression. J Clin Psychiatry 59(Suppl 14): 3.

Morgan WP (1985). Affective beneficence of vigorous physical activity. Med Sci Sports Exerc 17: 94-100.

Nawa H, Carnahan J, Gall C (1995). BDNF protein measured by a novel enzyme immunoassay in normal brain and after seizure: partial disagreement with mRNA levels. Eur J Neurosci 7: 1527-1535.

Nibuya M, Nestler EJ, Duman RS (1996). Chronic antidepressant administration increases the expression of cAMP response element binding protein (CREB) in rat hippocampus. J Neurosci 16: $2365-2372$.

Nibuya M, Morinobu S, Duman RS (1995). Regulation of BDNF and trkB mRNA in rat brain by chronic electroconvulsive seizure and antidepressant drug treatments. J Neurosci 15: 7539-7547.

Page ME, Brown K, Lucki I (2003). Simultaneous analyses of the neurochemical and behavioral effects of the norepinephrine reuptake inhibitor reboxetine in a rat model of antidepressant action. Psychopharmacology (Berl) 165: 194-201.

Russo-Neustadt A (2003). Brain-derived neurotrophic factor, behavior, and new directions for the treatment of mental disorders. Semin Clin Neuropsychiatry 8: 109-118.

Russo-Neustadt A, Beard RC, Cotman CW (1999). Exercise, antidepressant medications, and enhanced brain derived neurotrophic factor expression. Neuropsychopharmacology 21: 679-682.

Russo-Neustadt A, Ha T, Ramirez R, Kesslak JP (2001). Physical activity-antidepressant treatment combination: impact on brainderived neurotrophic factor and behavior in an animal model. Behav Brain Res 120: 87-95.

Russo-Neustadt AA, Beard RC, Huang YM, Cotman CW (2000). Physical activity and antidepressant treatment potentiate the expression of specific brain-derived neurotrophic factor transcripts in the rat hippocampus. Neuroscience 101: 305-312.

Samorajski T, Delaney C, Durham L, Ordy JM, Johnson JA, Dunlap WP (1985). Effect of exercise on longevity, body weight, locomotor performance, and passive-avoidance memory of C57BL/6J mice. Neurobiol Aging 6: 17-24.

Sanchez C, Hyttel J (1999). Comparison of the effects of antidepressants and their metabolites on reuptake of biogenic amines and on receptor binding. Cell Mol Neurobiol 19: 467-489.

Sapolsky RM (2000). The possibility of neurotoxicity in the hippocampus in major depression: a primer on neuron death. Biol Psychiatry 48: 755-765.

Smith MA, Makino S, Kvetnansky R, Post RM (1995). Stress and glucocorticoids affect the expression of brain-derived neurotrophic factor and neurotrophin-3 mRNAs in the hippocampus. J Neurosci 15(Part 1): 1768-1777.

Timmusk T, Palm K, Metsis M, Reintam T, Paalme V, Saarma M et al (1993). Multiple promoters direct tissue-specific expression of the rat BDNF gene. Neuron 10: 475-489.

Tse WS, Bond AJ (2002). Difference in serotonergic and noradrenergic regulation of human social behaviours. Psychopharmacology (Berl) 159: 216-221.

van Praag H, Kempermann G, Gage FH (1999). Running increases cell proliferation and neurogenesis in the adult mouse dentate gyrus. Nat Neurosci 2: 266-270. 